Ciência eNatura, Santa Maria, v. 37 Part 1 2015, p. 432-436

\title{
The effectiveness of positive psychotherapy on the psychological well- being of breast cancer patients
}

\author{
Zahra Jamshidifar ${ }^{1}$, Shohreh Mortezaei Shemirani ${ }^{2}$, Afshin Ahramian ${ }^{3}$, Armindokht \\ Ahmadi $^{4}$, Salva Shamsedini Lory ${ }^{5,}$, , Mohammad Moradi-Joo ${ }^{6}$
}

\author{
${ }^{1}$ Cancer Research Center, Shahid Beheshti University of Medical Sciences, Tehran, Iran \\ ${ }^{2} \mathrm{Ma}$, Department of Clinical Psychology, Islamic Azad University, Roudehen Branch, Roudehen, Iran \\ ${ }^{3} \mathrm{Ma}$, Department of Counseling, Boushehr University of Medical Sciences, Boushehr, Iran \\ ${ }^{4} \mathrm{PhD}$ Student, Department of Exceptional Children, Islamic Azad University, Science and Research \\ Branch, Tehran Branch, Tehran, Iran. \\ ${ }^{5}$ PhD Student, Department of Counseling, Young Researchers And Elite Club, Roudehen Branch, Islamic \\ Azad University, Roudehen, Iran. \\ ${ }^{6}$ Ms.C Health Technology Assessment (Tums) Cancer Research Center, Shahid Beheshti University of \\ Medical Sciences, Tehran, Iran \\ *corresponding author:mahoor princes@yahoo.com
}

\begin{abstract}
Many cancer patients become very anxious and stressed in response to cancer diagnosis. The fear of disease symptoms incidence, the loss of abilities and facing death, creates serious crisis for the patient and threatens one's well-being. This study aims to determine the effectiveness of positive psychotherapy on the psychological well-being of breast cancer patients. For this purpose, 24 patients with breast cancer in Shohada-e-Tajrish Hospital were selected through available sampling and were tested in terms of psychological well-being questionnaire. The results of analysis of covariance data, showed that positive psychotherapy is effective on the subscales of dominance, relationships and acceptance of psychological well-being in these patients but had no effect on the autonomy, growth, and goal. Therefore, this therapy can be used as an effective approach for the treatment of cancer patients.
\end{abstract}

Keywords: positive psychotherapy, psychological well-being and cancer 


\section{Introduction}

Diagnosis of cancer can make patients become very anxious and stressed in response to the initial diagnosis. The fear of disease symptoms incidence, the loss of abilities and facing death, creates serious crisis for the patient and emotionally puts one in a position that affects the treatment and threatens one's well-being. It also causes a person not to have an active participation in the treatment of his/her illness for failing to control their negative emotions (Shapiro, 2001; Peril, 2004; Badger, 2007). Cancer is a disease that could endanger a person's wellbeing. Psychological well-being has a significant role in various aspects of life such as social acceptance, having relationships with people, intimacy, sense of efficacy, having a social status, especially among youth (Ferkish, 2009). One of the main concepts of the model of health is well-being. Basically, there has been two basic approaches to define well-being. Approach based on hedonism, which believes that wellbeing means to maximize pleasure and minimize pain. That throughout history, has its own supporters such as Epicurus, Hobbes and Steward Mill. The second approach is based on Aristotle's virtue ethics. According to this approach, satisfying desires, despite making pleasure in us, does not always lead to wellbeing. Rather, well-being includes efforts to perfection and the realization of one's true potential which may not always be with a sense of pleasure (Ferkish, 2009). One of the problems that can endanger people's well-being is suffering from diseases, especially cancer. Growth of cancer in recent decades and its adverse effects on all aspects of physical, emotional, spiritual, social and economic, has caused not only the people but also the experts, to give more attention to the disease. It also introduces cancer as a major health problem of the century. In the meantime, many effective interventions have been carried out that positive psychotherapy uses techniques that leads to happiness, joy and prosperity. Also, this method emphasis on the importance of choosing a goal, focusing on the goal, the use of positive emotions, eliminating the vicious cycle of negative emotions, insisting on strategies for change, maintaining change, the usage of areas of strength, and the importance of considering the best aspects of human existence as the best solution to overcome man's confusion (Connolly, 2009). In this method, it is assumed that although negative emotions may be helpful in the short term (for example, in situations that are frightening, it activates fight and flight responses and protects the person) but being angry, afraid, worried, or stressed caused by negative emotions is harmful in the long run (Connolly, 2009; Wilson, 2008; Frijda, 1986). In contrast, positive emotions creates long-term benefits because the mental resource will expand, causing flexibility and psychological well-being and postpones the stimuli of negative emotions and causes emotional regulation (Miller, 2007; Frederickson, 2004). Thus, with reference to the above, our research aims to answer the question that whether positive psychotherapy is effective on the psychological well-being in patients with cancer?

\section{Method}

This is a quasi-experimental with a pretest, post-test design with control group. The study population included all the Shohada-eTajrish Hospital breast cancer patients in Tehran in 2013. 24 patients were selected from the population and randomly divided into experimental $(n=12)$ and control $(n=12)$ groups. The experimental group underwent positive psychotherapy in 8 sessions but the control group only received relaxation training.

\section{Tool}

Ryff's Psychological Well-Being Scale: According to Ryff's theory (1995) psychological well-being questionnaire includes six basic aspects. Ryff and Keyes (1955) calculated the reliability coefficient of the test between 0.86 to 0.93, on a sample of 321 cases of male and female subjects. Bayati and Kuchaki calculated the same amount from 0.81 to 0.88 (according to the Farkish, 2009). 


\section{Findings}

To investigate the effectiveness of positive psychotherapy on the psychological well-being of breast cancer patients, descriptive data (mean and standard deviation) is presented in Table 2.

Table 2: Mean and standard deviation of the components of well-being

\begin{tabular}{|c|c|c|c|c|}
\hline Variables & Group & Phase & Mean & SD \\
\hline \multirow[t]{4}{*}{ Autonomy } & \multirow[t]{2}{*}{ Control group } & Pretest & 49.25 & 5.61 \\
\hline & & Posttest & 43.91 & 9.01 \\
\hline & \multirow[t]{2}{*}{ Experimental group } & Pretest & 39.58 & 6.86 \\
\hline & & Posttest & 41.33 & 8.06 \\
\hline \multirow[t]{4}{*}{ Domination } & \multirow[t]{2}{*}{ Control group } & Pretest & 39.5 & 7.39 \\
\hline & & Posttest & 37.25 & 8.58 \\
\hline & \multirow{2}{*}{ Experimental group } & Pretest & 37.16 & 8.87 \\
\hline & & Posttest & 39.58 & 7.39 \\
\hline \multirow[t]{4}{*}{ Growth } & \multirow{2}{*}{ Control group } & Pretest & 49.33 & 5.61 \\
\hline & & Posttest & 49.25 & 5.46 \\
\hline & \multirow[t]{2}{*}{ Experimental group } & Pretest & 49.33 & 5.61 \\
\hline & & Posttest & 49.25 & 5.61 \\
\hline \multirow[t]{4}{*}{ Relationships } & \multirow[t]{2}{*}{ Control group } & Pretest & 39.58 & 6.86 \\
\hline & & Posttest & 40 & 7.71 \\
\hline & \multirow[t]{2}{*}{ Experimental group } & Pretest & 39.58 & 6.86 \\
\hline & & Posttest & 43.83 & 7.69 \\
\hline \multirow[t]{4}{*}{ Goal } & \multirow[t]{2}{*}{ Control group } & Pretest & 38.66 & 7.1 \\
\hline & & Posttest & 37.5 & 7.57 \\
\hline & \multirow[t]{2}{*}{ Experimental group } & Pretest & 38.66 & 7.1 \\
\hline & & Posttest & 38.58 & 7.3 \\
\hline \multirow[t]{4}{*}{ Acceptance } & \multirow[t]{2}{*}{ Control group } & Pretest & 44.16 & 7.64 \\
\hline & & Posttest & 43.91 & 7.76 \\
\hline & \multirow[t]{2}{*}{ Experimental group } & Pretest & 44.16 & 7.64 \\
\hline & & Posttest & 51 & 6.78 \\
\hline
\end{tabular}

According to Table 2 the mean of post-test scores in the experimental group of components of autonomy, dominance, relationships and acceptance were more than the pre-test scores. The mean of post-test scores in the experimental group of components of growth and goal were less than the pre-test scores. Although the pretest scores of the two groups is close to each other, there is a significant difference in their post-test scores. Then, by using inferential statistics (MANCOVA) we will examine the significance of these differences.

Table 3: MANCOVA effectiveness of positive psychotherapy on components of well-being

\begin{tabular}{|c|l|c|c|c|c|c|}
\hline \multicolumn{2}{|l|}{ Name Test } & Amount & F & Df hypothesis & Df error & Level Significant \\
\hline \multirow{3}{*}{ Group } & Pillai's Trace Test & 0.73 & 5.12 & 6 & 11 & 0.01 \\
\cline { 2 - 7 } & Wilks' lambda test & 0.26 & 5.12 & 6 & 11 & 0.01 \\
\cline { 2 - 7 } & Hotelling trace test & 2.79 & 5.12 & 6 & 11 & 0.01 \\
\cline { 2 - 7 } & Roy's largest root test & 2.79 & 5.12 & 6 & 1 & 0.01 \\
\hline
\end{tabular}


As shown in Table 3, findings from MANCOVA indicates that multivariate $\mathrm{F}$ value at the level of $\mathrm{P}<0.0001$ is statistically significant. Therefore, we can say there is a significant differences between the experimental and control groups in at least one of the dependent variables. To discover the difference, the results of the test effects among subjects is presented in Table 4 .

Table 4: Results of MANOVA on the difference between the components of well-being

\begin{tabular}{|l|l|c|l|l|l|}
\hline \multicolumn{1}{|c|}{ Variables } & Total Square & Degrees of freedom & Mean square & F value & Significance level \\
\hline Autonomy & 2.37 & 1 & 2.37 & 0.11 & 0.74 \\
\hline Domination & 90.06 & 1 & 90.06 & 8.9 & 0.00 \\
\hline Growth & 0.00 & 1 & 0.00 & 0.01 & 0.89 \\
\hline Relationships & 70.56 & 1 & 70.56 & 7.87 & 0.01 \\
\hline Goal & 21.45 & 1 & 21.45 & 1.92 & 0.18 \\
\hline Acceptance & 140.38 & 1 & 140.38 & 14.35 & 0.00 \\
\hline
\end{tabular}

As shown in table 4, the mean difference between control and experimental groups (pretest-posttest) has a significant difference in dominance, relationships and acceptance. As well as the mean difference between control and experimental groups (pretest-posttest) have no significant difference in autonomy, growth and goal. Therefore, by the studies on the effectiveness of positive psychotherapy on the psychological well-being of women with breast cancer, we found that the experimental group and the control group experienced greater wellbeing. Positive psychotherapy has helped to the well-being of patients with breast cancer.

\section{Conclusion}

In the study of the research hypothesis based on the effectiveness of positive psychotherapy on the psychological well-being, the findings indicated that this treatment is effective in the subscales of dominance, acceptance and relationships in breast cancer patients. But there is no significant effect in the subscales of autonomy, growth and goal. These findings are in line with the results of Conoley, \& Conoley(2007), Dockray\& Steptoe(2010) and Connelly \& Denney(2007). In explaining these findings we can say that it seems that positive psychotherapy can not only make a positive resource but it can also have a mutual impact on negative syndrome as well as being a barrier for its recurrence. Research-based on meaning in the form of positive psychotherapy also shows that people who have used the meaning to change the cycle of misery into happiness make the most of their treatment programs.

According to positive psychology under the terms of disaster survival and durability condition is dependent on two functions, personal characteristics and value systems related to their group or community. In fact the ultimate goal of positive approach is to identify methods which causes well-being and happiness in people, by focusing on the talents and capabilities of people instead of dealing with abnormalities and disorders (Connolly, 2009). However, since the purpose and orientation in life is the ability to find meaning, and to follow it which all of these are in opposition to happiness, personal growth or the blossoming of all the forces and their self-talents, depends on nurturing and obtaining new abilities that are required to deal with difficult situations and problems to other variables and capabilities of people. Because facing these situation makes one to seek one's inner forces and also gain new abilities. It had no significant difference with positive training. In fact, if we want to know when it is most likely to find these forces?

When a person is under pressure, these talents are discovered frequently and show their power 
to change the situation. Self-actualization of people during challenges and unpleasant conditions, expresses human mental ability to cope with problems, endure a lot of suffering and return back to normal after leaving it behind and progress after passing obstacles. Autonomy in these people also means that the people can act and live according to their beliefs and living standards, even if it is against the accepted beliefs and customs in society. Jang (1993), emphasis that a fully grown man and self-flourish is the one whom is free from any age and society. Therefore, a person who chooses such an approach to life, is usually familiar with its consequences and has accepted it. Therefore, positive perspective training has no significant effect on these variables.

\section{References}

Alberto, J., \& Joyner, B. (2008). Hope, optimism, and self-care among Better Breathers Support Group members with chronic obstructive pulmonary disease. Applied Nursing Research, 21(4), 212-217.

Connelly, M., Denney, D.R (2007).Regulation of Emotions during experimental stress in alexithymia. Journal of Psychosomatic Research, 62, 649-656.

Conoley, C. W., \& Conoley, J. C. (2009). Positive psychology and family therapy: creative techniques and practical tools for guiding change and enhancing growth: Wiley.

Conoley, C.W., Conoley, J.C (2009).Positive psychology and family therapy. NewJersey. Wiley. ISBN.

Dockray, S., \& Steptoe, A. (2010). Positive affect and psychobiological processes. Neuroscience \& Biobehavioral Reviews, 35(1), 69-75. doi: 10.1016/j.neubiorev.2010.01.006

Duarte, C. S., Bordin, I. A., Yazigi, L., \& Mooney, J. (2005). Factors associated with stress in mothers of children with autism. Autism, 9(4), 416-427. doi: 10.1177/1362361305056081
Fredrickson B.L. (2004).The broaden and build theory of positive emotions. Philosophical transactions: Biological scienses 359(1449).

Frijda, N.H (1986). The emotions. Cambridge, England: Cambridge University Press.

Miller, D.N., Nickerson, A (2007).Changing the past, present and future: potential applications of

positive psychology in school - based psychotherapy with children and youth. Journal of Applied School Psychology, 24(1):61-147.

Pril, WF (2004). Eviedence report on the occurrence, assessment and treatment of depression in cancer patients. J Nath Cancer Institute Monographs, 32:32-39.

Badger, T.,Segrin, C., Dorros, S M.,Meek P., Lopez, A M.(2007). Depression and anxiety in women with breast cancer and their partners. Journal of Nursing Research.Vol 56, No 1.

Shapiro, S.L.,Lopez, A.M., Scharrz, G.E.(2001). Quality of life and breast cancer relationship to psychosocial variable. Journal of Cline psycol 5(1):501-519.

Wilson, A.L (2008). Word 's worth: A biblio/ poetry therapy guide for teens and their caregivers. Capston paper for master of liberal studies, Denver University. 